\title{
EDITORIAL: CLOSING IN, OPENING OUT
}

\author{
Christopher Fox
}

This issue goes to press at a moment when it seems as if, across the world, some of the restrictions imposed by the pandemic may be easing. Thankfully, the three-month delay of TEMPO's production cycle means that I cannot say any more than that; thankfully, it also means that no one has to read my thoughts on the 'lost year', the 'year without new music' or any other formulation of the experience we have all shared.

How will we remember the Plague Year? It's impossible to say, so let us instead look at the ways in which musical practice has opened out over recent decades. This is, at least, a perspective that allows us to think about the six articles in the first section of this issue. Their subjects are varied, from aspects of composition in the work of four very different composers, to a new deployment of the role of the conductor, to new music using instruments more usually associated with historically informed performance; but what informs them all is a very tight focus, a deliberate closing in of attention.

This is what many composers and performers do, of course. Distinctiveness can often be achieved just by ignoring a lot of the things that are conventionally assumed to be significant. Distinctiveness is useful for marketing, too. I knew about Pierluigi Billone, for example, some time before I had heard any of his music, because he was the pioneer of 'de-coupling', writing music in which instrumentalists' fingers, breath, bows and lips act in counterpoint as well as in unison. Similarly, Howard Skempton's achievements as a composer are often distilled into a single epithet, 'miniaturist', because his output is full of very short pieces.

In the long run, these labels may not be very helpful: 'decoupling' suggests something abstract, diffuse, entirely at odds with the visceral intensity of Billone's best work; 'miniature' is not a word that explains Skempton's Viola Concerto or his string quartet Tendrils. Yet these are also more than just marketing slogans. Why is Rebecca Saunders frequently described as a composer whose music is preoccupied with instrumental timbre? Because she creates music in which many of the other elements that usually play a part in characterising a particular work or compositional style - melody, harmony, rhythm - have been assigned much less significant roles than timbre.

For people who write about music there is a challenge in each of these acts of closing in. The history of art music in the European classical tradition has privileged certain sorts of discourse, particularly those that relate to pitch and form, and this has created a culture of esteem in which complex, extended works that demonstrate sophisticated pitch organisation have been afforded the highest value. My experience of five years as editor of TEMPO suggests that this is still the case, but it is also not surprising. The methodologies for the analysis of other musical domains and the vocabularies, both verbal and visual, for articulating that analysis are still in the early stages of their development. 
So it is more straightforward, perhaps, for Howard Skempton to discuss the compositional processes at play in his enigmatically compact set of 24 preludes and canons because these processes centre on pitch. Tobias Schick's article (in an excellent translation by Neil Thomas Smith - the world of Anglophone musicology remains very dependent on such selfless work) about Billone is necessarily less precise in its account of how his music is made, but is an excellent introduction to a range of work by a composer who has not featured in this journal before. Omri Abram, on the other hand, performs another act of closing in, looking in considerable detail at just two works, Ire and Still, and in so doing begins to develop a methodology for timbral analysis that may well prove to be more generally useful.

To close in, then, may also be to open out. Not a new thought today, nor a new thought when William Blake wrote that it was possible 'to see a World in a Grain of Sand', nor when Julian of Norwich saw 'a little thing, the quantity of a hazel nut, lying in the palm of my hand... and thought, "What may this be?" And it was answered generally thus, "It is all that is made."' But, after a year of mostly being closed in, it may be a reassuring thought. 